University of Louisville

ThinkIR: The University of Louisville's Institutional Repository

$12-2014$

\title{
Is it the thought that counts? : investigating children's understanding of helpfulness, effort, and utility.
}

Danielle McCarty

University of Louisville

Follow this and additional works at: https://ir.library.louisville.edu/honors

Part of the Child Psychology Commons, and the Cognitive Psychology Commons

\section{Recommended Citation}

McCarty, Danielle, "Is it the thought that counts? : investigating children's understanding of helpfulness, effort, and utility." (2014). College of Arts \& Sciences Senior Honors Theses. Paper 42.

http://doi.org/10.18297/honors/42

This Senior Honors Thesis is brought to you for free and open access by the College of Arts \& Sciences at ThinkIR: The University of Louisville's Institutional Repository. It has been accepted for inclusion in College of Arts \& Sciences Senior Honors Theses by an authorized administrator of ThinkIR: The University of Louisville's Institutional Repository. This title appears here courtesy of the author, who has retained all other copyrights. For more information, please contact thinkir@louisville.edu. 


\author{
Is it the Thought that Counts? \\ Investigating Children's Understanding of Helpfulness, Effort, and Utility \\ Danielle McCarty \\ University of Louisville \\ Senior Honors Thesis
}

\begin{abstract}
Author's Note
Acknowledgements. Thanks to Asheley Landrum, $\mathrm{PhD}$, and Patrick Shafto, $\mathrm{PhD}$, without whom this study could not have occurred; as well as Marena Eglian, Katlyn Kermicle, Adam Bamforth, and the other members of the Computational Cognitive Science Lab.
\end{abstract}




\begin{abstract}
How do children consider helpfulness, specifically effort and utility, when evaluating potential informants? We tested preschoolers on three conditions, asking them to choose between a character high in both effort and utility and a character who acted with either 1) low effort and high utility, 2) high effort and low utility, or 3) low effort and no utility (removed from social contexts). The opposing characters provided conflicting information when labeling novel objects, and participants were asked which label they endorsed. They were then asked to choose which character was the more helpful, which worked harder, and which was nicer. We found trends toward endorsing words from the helpful over no social context character. Participants chose the helpful character as more helpful and hardworking compared to the low utility character, and as working harder compared to the no social context character. These trends indicate that children focus on utility and social contribution over effort when evaluating the helpfulness of a potential informant.
\end{abstract}




\section{Is it the thought that counts?}

\section{Investigating children's understanding of helpfulness, effort, and utility}

Much of our knowledge has been acquired not from direct observation but from the testimony of others (e.g., Koenig \& Harris, 2005). However, not all informants are equally worthy of trust - they may be incompetent, irrelevant, ignorant, deceptive, or unpleasant (e.g., Mascaro \& Sperber, 2009). Because of this, it is important to be able to determine whether a potential informant is trustworthy — able and willing to provide accurate information.

Primary to whether a child trusts information from an informant is the child's evaluation of that informant's positive (or negative) capacities in intellectual and social dimensions (Fiske, Cuddy, \& Glick, 2007; see also Landrum, Mills, \& Johnston, 2013; Mascaro \& Sperber, 2009; Shafto, Eaves, Navarro, \& Perfors, 2012). Typically, an informant's capacity on the intellectual dimension has been understood as competence (e.g., Fiske et al., 2007; Mascaro \& Sperber, 2009; Landrum et al., 2013) and measured in terms of characteristics that indicate an informant's ability to provide accurate information, such as prior history of accuracy (e.g., Brosseau-Liard \& Birch, 2010; Koenig \& Harris, 2005), expertise (e.g., Aguiar, Stoess, \& Taylor, 2012; Landrum et al., 2013; Lutz \& Keil, 2002), and relevance to the domain at hand (e.g., Danovitch \& Keil, 2007). Informants' capacities on the warmth dimension have included such concepts as intention (e.g., Mascaro \& Sperber, 2009) and affect (i.e., the informant's demeanor, or degree of niceness or meanness; Landrum et al., 2013).

Generally, research has indicated that children prefer to learn from informants who are competent, have a history of accuracy, and are able to provide task-relevant information (see Mills, 2013, for a review). For example, with regard to competence, Cluver, Heyman, and Carver (2013) found that children as young as 20 to 24 months prefer to seek information from "good 
helpers" rather than "bad helpers" when solving problems. That is, they preferred those who had previously demonstrated the correct way to access a novel toy and demonstrated high levels of social engagement (e.g., varied voice pitch, made frequent eye contact) over those who had demonstrated an incorrect way to access a novel toy and had shown low levels of social engagement (e.g., spoke in monotone voice, avoided direct eye contact). Similarly, regarding a history of providing accurate information, both 3- and 4-year-olds preferred to endorse information from a previously accurate informant over a previously inaccurate one (Koenig \& Harris, 2005). Finally, with regard to the provision of task-relevant information, research finds that, by the age of 4 , children demonstrate an understanding of experts and the sort of knowledge they would be expected to possess. For example, children are able to attribute domain-relevant information to the proper expert, ascribing medical knowledge to a doctor rather than a car mechanic (Lutz \& Keil, 2002). Moreover, by the $2^{\text {nd }}$ grade, children presented with a dilemma are able to apply this understanding by choosing problem-solving advisors based on whether or not they had expertise relevant to the domain in which the dilemma occurred (Danovitch \& Keil, 2007).

An informant's capacity on the "warmth" dimension of social cognition (Fiske et al., 2007) has also been shown to be important in making epistemic choices. Research by Mascaro and Sperber (2009) found that children prefer to trust a benevolent informant (kind, wellintentioned) over a malevolent informant (unkind, mal-intentioned). By age 3, children prefer to believe information provided by a benevolent informant over a malevolent one, and by age 5 , children are able to make more sophisticated inferences, anticipating, for example, that someone described as intending to deceive the participant is likely telling falsehoods. Additional research has expanded this finding by showing that 4-year-olds exhibit an understanding of the probable 
helpfulness of "helpers" and "trickers," but only by age 5 do they apply this knowledge in choosing a helpful informant over a deceptive one (Vanderbilt, Liu, \& Heyman, 2011).

In order to understand how children jointly weigh these sorts of factors when making epistemic judgments, studies have begun to examine two or more of these factors together (e.g., Landrum et al., 2013; Lane, Wellman, \& Gelman, 2013). Although preschool-age children have been found to trust a relevant expert over an irrelevant expert, and a nice expert over a mean expert, when competence and benevolence information conflicts (e.g., a mean expert), children endorse information from a nice non-expert over that from a mean expert. (Landrum et al., 2013). Examining the question from a different perspective, Liu, Vanderbilt, and Heyman (2013) found that 5- and 6-year-olds take both informant intent and reliability into account when choosing whom to trust: children tend to prefer informants with benevolent intent regardless of the accuracy of their testimony, but they also tend to prefer informants with previous accurate testimony regardless of inferred intent. This research is consistent with findings indicating that children tend to have a preference for positively-valenced informants, that is, a "halo effect" (e.g., Boseovski, 2012), and that children tend to have an aversion to negatively valenced informants, that is, a "pitchfork effect" (Koenig \& Jaswal, 2011).

One facet of the field of epistemic judgment which has yet to be investigated in depth is how children evaluate informants within the "warmth" dimension of social cognition (Fiske et al., 2007). Several studies have linked this social dimension with various informant features, such as intention (Liu et al.; Vanderbilt et al., 2011), niceness or kindness (Landrum et al., 2013; Lane et al., 2013), and helpfulness (e.g., Shafto et al., 2012). Although research has shown that, for example, children prioritize informant niceness over expertise (Landrum et al., 2013) and intention over accuracy (Liu et al., 2013), it is unclear how children are conceptualizing the 
social dimension. Are they thinking of it simply in terms of positive affect (e.g., trusting a nice person whether or not he/she is particularly helpful)? Or, do children demonstrate more sophisticated inferences that show they understand what it means to be helpful? That is, do they understand that helpfulness is more than just being nice or being willing to put forth effort, but requires providing task-relevant assistance that helps achieve a goal?

The current study begins to examine these open questions. Specifically, we investigate how children weigh effort and task relevance (i.e., utility) when making epistemic judgments. Does an individual's high level of effort exerted imbue him or her with positive social valence, even if his or her efforts are fruitless? Or does an individual's constructive contribution to a goal speak more to his or her helpfulness and social valence than does their level of effort? In this study, we specifically wished to examine how children evaluated individuals who differed in their levels of demonstrated effort and utility as well as whether children would leverage this experience to trust an informant in a novel word learning task (e.g., Koenig \& Harris, 2005). In this context, effort is defined as "a strenuous putting forth of power, physical or mental; a laborious attempt; a struggle" (OED, n.d.). Though both mental and physical exertion would be worthwhile concepts to examine, in this study we chose to consider the more tangible and testable concept of physical effort in an attempt to ensure that the type of effort tested was consistent throughout the study. Utility here is defined as "the fact, character, or quality of being useful or serviceable; fitness for some desirable purpose or valuable end; usefulness, serviceableness" (OED, n.d.). Rather than examining the philosophical or economic constructs of utility, this study again focused on the more concrete concept of being serviceable in reaching a valuable end. Crossing these two features, along with niceness, allows us to examine how children are weighing different types of features along the social dimension. 


\section{Method}

We presented children with two opposing characters: one character always performed actions indicating a high level of both effort and utility to a goal and a second character who performed actions exemplifying various combinations of high and low effort and utility, as described below. Thus we could examine whether children focus more on cues indicating a character's effort or utility in choosing from whom they would like to learn. Examining children's perceptions of and choices regarding characters who varied in both effort and utility, enabled us to make inferences about how children understand these concepts in relation to one another-that is, how they are conceptualizing the warmth dimension of social cognition.

\section{Participants}

Twenty-four participants, including fourteen females and ten males (age: $M=4.05$ years; range: $3.08-5.07$ years) were recruited from local preschools in the Louisville Metro area. This range of ages is in keeping with research indicating that many of children's epistemic judgment capabilities develop during this time (e.g., Mascaro \& Sperber, 2009; Vanderbilt et al., 2011).

\section{Procedure}

This experiment used a within-subjects design to test three scenarios (i.e., conditions; see Table 1). In each condition, children were introduced to a set of characters (during a training phase) and then answered a series of questions (during a testing phase). These procedures are described in more detail below.

Table 1. Examples of each condition and scenario from the study. While we kept the order of the scenarios consistent, the order of the conditions was counterbalanced between participants. In addition, we counterbalanced which character was presented first, as well as character names and appearances.

\section{Scenarios}

\begin{tabular}{llll} 
& \multicolumn{1}{c}{ Block tower } & Pulling Weeds & \multicolumn{1}{c}{ Jar of Candy } \\
\hline Dilemma & $\begin{array}{l}\text { Arms hurt too badly to carry the } \\
\text { very last block all the way over }\end{array}$ & $\begin{array}{l}\text { Too tired and sore } \\
\text { from pulling weeds }\end{array}$ & $\begin{array}{l}\text { Jar with favorite } \\
\text { candy inside is stuck }\end{array}$ \\
\hline
\end{tabular}




\begin{tabular}{llll}
\hline & $\begin{array}{l}\text { from across the room and place } \\
\text { on top of the block tower. }\end{array}$ & $\begin{array}{l}\text { from a flower garden } \\
\text { for a long time and } \\
\text { needs help to finish. }\end{array}$ & $\begin{array}{l}\text { and will not come } \\
\text { open no matter how } \\
\text { hard she tries. }\end{array}$ \\
\hline $\begin{array}{l}\text { Helpful } \\
\text { Character }\end{array}$ & $\begin{array}{l}\text { Works a lot to carry block from } \\
\text { across the room and places it on } \\
\text { top of the tower. }\end{array}$ & $\begin{array}{l}\text { Works a lot to pull } \\
\text { strong weeds from the } \\
\text { tough ground in the } \\
\text { garden. }\end{array}$ & $\begin{array}{l}\text { Works a lot with the } \\
\text { main character to } \\
\text { open her jar until it } \\
\text { finally opens. }\end{array}$ \\
$\begin{array}{llll}\text { Low Utility } \\
\text { Character }\end{array}$ & $\begin{array}{l}\text { Works a lot to push a heavy } \\
\text { desk from across the room to }\end{array}$ & $\begin{array}{l}\text { Works a lot to wash } \\
\text { the dirty windows of } \\
\text { the house. }\end{array}$ & $\begin{array}{l}\text { Works a lot to open a } \\
\text { box of toys until it } \\
\text { finally opens. }\end{array}$ \\
$\begin{array}{llll}\text { Londition 1 } 1 \\
\text { Informant }\end{array}$ & $\begin{array}{l}\text { Works a little to slide a block } \\
\text { from across the room with her } \\
\text { foot so it is next to the main } \\
\text { character. }\end{array}$ & $\begin{array}{l}\text { Works a little to bring } \\
\text { the main character a } \\
\text { shovel and gloves to } \\
\text { use in pulling weeds. }\end{array}$ & $\begin{array}{l}\text { Works a little to hand } \\
\text { the main character a } \\
\text { towel aid in opening } \\
\text { the jar. }\end{array}$ \\
\hline $\begin{array}{l}\text { No Social } \\
\text { Context } \\
\text { Character }\end{array}$ & $\begin{array}{l}\text { In an empty room, works a lot } \\
\text { to carry a block from across the } \\
\text { room and place on top of the } \\
\text { tower. }\end{array}$ & $\begin{array}{l}\text { At an empty house no } \\
\text { one lives in, works a } \\
\text { lot to pull up weeds } \\
\text { from that garden. }\end{array}$ & $\begin{array}{l}\text { In an empty room, } \\
\text { finds a jar of candy } \\
\text { and works a lot to } \\
\text { open it. }\end{array}$ \\
\hline
\end{tabular}

\section{Training phase.}

For each condition's training phase, children were shown illustrations introducing them to two similar scenarios in adjacent locations. This method of using pictures and brief narrations to introduce a character and his/her traits was based on the method used by Lane, Wellman, and Gelman (2013). In two of the conditions, children were presented with two initial characters (one in each location) that faced identical dilemmas (e.g., building a block tower with heavy blocks) that an additional character (i.e., a friend who might plausibly share the main character's goal) could potentially help resolve (see Figure 1). Each of the two friends performed a different action based on the condition in which they occur. In the third condition (explained in more detail below), there was not an initial character facing a dilemma in one of the two locations as this condition was intentionally not goal-oriented (and thus, non-social). In this condition, the friend was present and engaging in an action, but alone. 


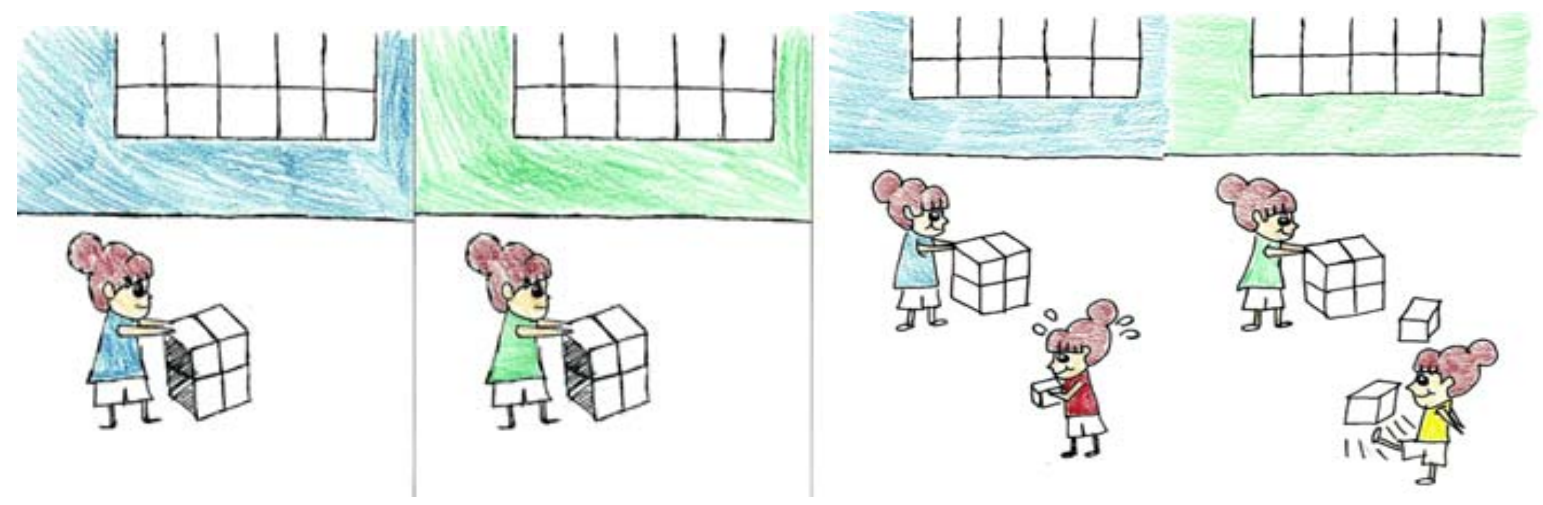

Figure 1. The first two images from Condition 1. The first image introduces the two initial characters with an identical dilemma (in this case, completing a block tower). The second image introduces two friends with different ways of responding to this dilemma.

Character A in each condition always performed actions characterized by exerting a high level of physical effort and a high level of utility (usefulness, relevance) to a friend's goal, whereas Character B performed actions which were different in each condition. Below, Character A will be referred to as the "Helpful Character" and Character B will be referred to by the characteristic which differentiates him/her from Character A. In Condition 1, Character B (i.e., Low Effort Character) was characterized as having low effort but high utility: s/he performed actions which required little physical effort, yet did have utility toward his/her and the first character's shared goal. In Condition 2, Character B (i.e., Low Utility Character) was characterized as having high effort but low utility: s/he performed actions which required great physical effort, yet did not have utility toward the shared goal. Condition 3, the "no social information" condition, was distinct from Conditions 1 and 2. In this condition, Character B (i.e., No Social Context Character) was characterized by having high effort but no utility: s/he performed actions which were identical to those in Condition 1 (requiring great physical effort and accomplishing some task), yet this character was in a scenario in which no other individuals were present, and therefore had no social context or shared goal. Thus his or her completed 
action technically had no utility, as it did not contribute to solving a problem or reaching a goal.

There were three potential preschool-level dilemmas or problems to be dealt with. See Table 1 above for details regarding each dilemma and the way each character responded.

\section{Testing phase.}

During the testing phase, participants were asked a series of three types of question items designed to infer their perception of each character and the epistemic choices they would make regarding the characters: endorsement items, memory check items, and explicit judgment items. Each of these item types are discussed in more detail below.

\section{Endorsement items.}

In each condition, children were shown photographs of four novel objects (i.e., unusual kitchen gadgets), and each of the two characters provided conflicting information as to what the proper name for the novel object is. These pairs of words for labeling novel objects (e.g., Wug and Dax, Merval and Feppin) were taken from the study by Landrum et al. (2013), which similarly presented children with a novel word-pairs task. With each novel object and pair of words, children were asked which of the two characters they believed was most likely providing the correct name for each of four novel objects. For instance, participants might have heard, 'Here's what the first toy looked like. Brooke said it's a Wug and Julie said it's a Dax. Who do you think is right? Point to their picture." Thus, we used the number of times out of four that children chose to learn from the Helpful Character as the dependent variable in order to measure their overall preference for learning from one type of informant over another.

\section{Memory check items.}

Next, for the memory check items, children were asked which character performed which action in order to determine whether children were accurately tracking the information provided 
about each character. For example, in the "block tower" scenario of Condition 1, participants were asked "Who carried a heavy block across the room to Mary, Brooke or Julie? And who slid a block across the room with her foot, Brooke or Julie?" These responses were used later to determine whether children who responded accurately to these questions had significantly different responses in the endorsement items and explicit judgment items than those who did not remember accurately.

\section{Explicit judgment items.}

Finally, for the explicit judgment items, children were asked to provide ratings indicating their perceptions of each character as helpful, effortful, and nice. Participants were asked Yes or No questions about each character and whether or not they were helpful. A forced-choice question was then asked about which character the participant believed was the most helpful. The number of times participants responded that the Helpful Character in every condition and the Low Effort (but high utility) Character in Condition 1 were helpful and the number of times they chose the Helpful Character as the more helpful were the dependent variables.

Next, participants were asked how hard each character worked. They were given similar Yes or No questions asking whether or not each character worked hard, then a forced-choice question asking which character worked harder. The number of times participants responded that the Helpful Character in every condition, Low Utility (but high effort) Character in Condition 2, and No Social Context (but high effort) Character in Condition 3 worked hard and the number of times they chose the Helpful Character as the hardest working were the dependent variables.

Finally, participants were asked to rate how nice each character was. They were again given two Yes or No questions, now asking if each character was nice, and were then given a forced-choice question to determine which they perceived as being nicer. The number of times 
participants responded that the Helpful Character in every condition, Low Effort (but high utility) Character in Condition 1, and Low Utility (but high effort) Character in Condition 2 were nice and the number of times they chose the Helpful Character as the nicer were the dependent variables.

After each child had completed the study, s/he was thanked for his/her participation, given a certificate, and allowed to choose a small toy.

\section{Results}

First, we compare novel word endorsement and explicit judgment item results from each condition to one another in order to determine if there are any differences between conditionsthat is, if participants trust differently when considering various characters who differed in effort and utility. Then, we consider each condition independently, comparing children's endorsements and explicit judgment responses to chance levels in order to determine if the manipulation in each condition had an effect. Overall, participants were $61 \%$ accurate on the memory check items. There were no significant differences between responses of participants who answered correctly on the memory check items and those that did not; therefore, memory check responses were excluded from further analyses.

\section{Comparisons across conditions}

First, we were interested in whether the number of endorsements for the Helpful Character varied based upon condition (with whom the Helpful Character was paired). That is, we wished to test whether children responded differently when presented with different characters depicting different levels of effort and utility. To do this, we conducted a repeatedmeasures ANOVA on the number of endorsements for the Helpful Character across the three within-subjects conditions. We found no significant differences in number of endorsements for 
the Helpful Character between the three conditions, $F(2,46)=0.793, p=.459, \eta_{\mathrm{p}}{ }^{2}=.033$. See Figure 2.

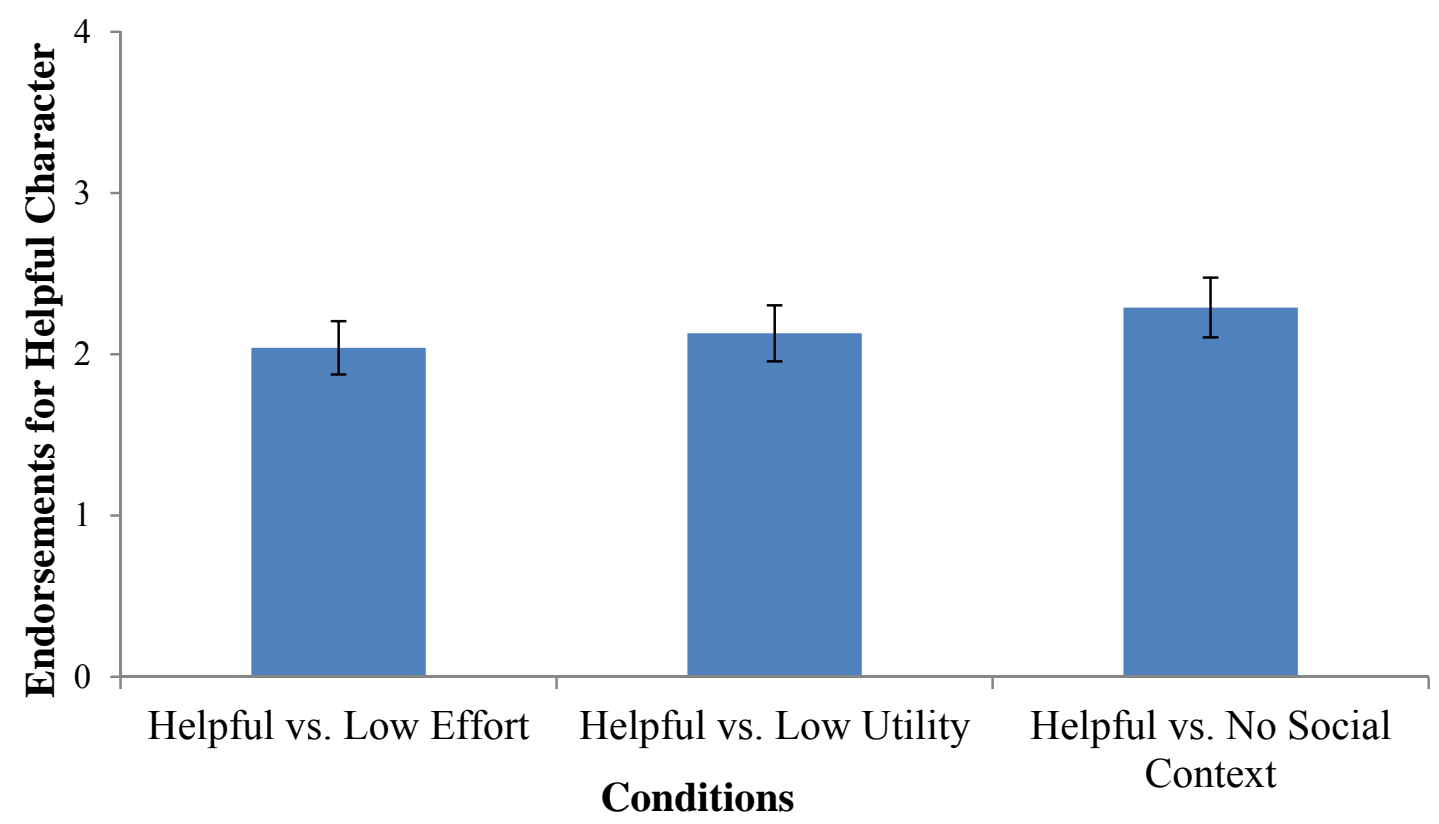

Figure 2. Means of endorsements for Helpful Character in each condition.

Second, we were interested in how children's explicit judgments varied between conditions, in order to determine whether their perceptions of characters varied as the characters' levels of effort and utility varied. First, we conducted a chi-square test on the number of times participants preferred the Helpful Character as being the more helpful across conditions. There was a trend toward significance in participants' responses, $\chi^{2}(2)=4.97, p=0.08$. The greater frequency with which children favored the Helpful Character when s/he was opposed to the Low Utility and No Social Context Characters indicates that they tend to perceive characters with high utility as more helpful than those with lower utility. This suggests that children judge helpfulness differently when effort and utility varied. Second, we conducted a similar chi-square test analyzing the number of times children selected the Helpful Character as having worked harder, 
$\chi^{2}(2)=4.03, p=0.13$. These results suggest that children judge effort differently when utility and effort varied between characters. Children favored the Helpful Character more frequently in the Low Utility and No Social Context Conditions, indicating that they tend to perceive characters with high utility as having worked harder than those with lower utility. Finally, we conducted a chi-square test analyzing the number of times children selected the Helpful Character as being nicer across the three within-subjects conditions, $\chi^{2}(2)=2.12, p=0.35$. This would suggest that children do not judge niceness differently when characters vary in utility and effort.

\section{Condition 1: Helpful vs. Low Effort (but high utility) Character condition}

In the helpful versus low effort yet high utility condition, we hypothesized that participants would prefer to learn novel words from characters exhibiting high levels of effort over those who exhibit low levels. A single-sample $t$-test found that participants did not differently endorse the novel words from the Helpful Character above chance levels, $M=2.04$, $S D=0.806, S E=0.165$, thus not showing a strong preference for either character $t(23)=0.253$, $p=.802, d=0.11$. That is, participants viewed the Helpful and Low Effort Characters similarly when making epistemic judgments.

Next, we hypothesized that participants would perceive both characters as helpful, as they both demonstrated high utility, yet would perceive the high effort character as being the more helpful of the two. Participants did perceive the Helpful Character as helpful: 23 of 24 participants rated him/her as such, .96 observed proportion (compared with .50 chance proportion), $p<.001$ by a one-tailed binomial test. Nineteen of twenty-four participants also rated the Low Effort Character as helpful, .79 observed proportion, binomial test $p<.001$. Contrary to the hypothesis, participants did not see either character as significantly more helpful 
(Helpful Character: $n=10$, observed proportion $=.42$; Low Effort Character: $n=14$, observed proportion $=.58$; one-tailed binomial test: $p=.271)$.

We then hypothesized that participants would perceive the high effort, but not the low effort, character as having worked hard, and would perceive the high effort character as having worked the harder of the two. Participants perceived both characters as having worked hard (Helpful Character: $n=22$, observed proportion $=.92, p<.001$ in a binomial test; Low Effort Character: $n=20$, observed proportion $=.83, p<.001$ in a binomial test). Nor did participants select the Helpful Character as having worked the harder of the two (Helpful Character, $n=12$, observed proportion $=.50$; Low Effort Character: $n=12$, observed proportion $=.50$; binomial test: $p=.581)$

Finally, we hypothesized that participants would perceive both characters as nice, and would perceive the high effort character as the nicer of the two. Participants did perceive both characters as being nice (Helpful Character: $n=23$, observed proportion $=.96, p<.001$ in a binomial test; Low Effort Character: $n=23$, observed proportion $=.96, p<.001$ in a binomial test). However, participants did not significantly rate the Helpful Character as the nicer of the two (Helpful Character, $n=10$, observed proportion $=.42$; Low Effort informant: $n=14$, observed proportion $=.58$; binomial test: $p=.271$ ).

In sum, when considering characters who each demonstrate high utility yet vary in effort, children view both characters as helpful, as working hard, and as nice. Children's responses indicate that they do not differentially trust characters who vary in effort, as they neither show a preference in novel word endorsements nor in rating one character as more helpful, as working harder, or as nicer.

\section{Condition 2: Helpful vs. Low Utility (but high effort) Character condition}


In the helpful vs. low utility yet high effort condition, we hypothesized that participants would prefer to learn novel words from characters exhibiting high levels of utility over those who exhibit low levels. In four trials, participants did not show any preference for learning novel words from the Helpful Character as compared to the Low Utility Character, $M=2.13, S D=$ $0.85, S E=0.174$, and in fact did not show a strong preference for either character $t(23)=0.720$, $p=.479, d=0.30$ by a single-sample $t$-test. Thus participants showed no evidence of preferential trust when considering a character with high utility and one with low utility.

We next hypothesized that participants would perceive the high utility, but not the low utility, character as having been helpful, and would perceive the high utility character as being the more helpful of the two. Participants perceived both characters as being helpful, contrary to the hypothesis (Helpful Character: $n=21$, observed proportion $=.88, p<.001$ in a binomial test; Low Utility Character: $n=22$, observed proportion $=.92, p<.001$ in a binomial test). Participants significantly rated the Helpful Character as the more helpful of the two (Helpful Character, $n=17$, observed proportion $=.71$; Low Utility Character: $n=7$, observed proportion $=.29$; one-tailed binomial test: $p=.032$ ). This finding indicates that children were able to detect a difference in the characters' respective levels of utility, and therefore chose the Helpful Character as the more helpful of the two.

We also hypothesized that participants would perceive both characters as having worked hard, as they both demonstrated high effort, and yet would perceive the high utility character as having worked the harder of the two. Participants did perceive both characters as having worked hard (Helpful Character: $n=18$, observed proportion $=.75, p<.001$ in a binomial test; Low Utility Character: $n=22$, observed proportion $=.92, p<.001$ in a binomial test). As hypothesized, participants did rate the Helpful Character as having worked the harder of the two 
(Helpful Character, $n=18$, observed proportion $=.75$; Low Utility Character: $n=6$, observed proportion $=.25$; one-tailed binomial test: $p=.011)$. Though both characters demonstrated high levels of effort, participants showed a preference for rating the Helpful Character as working the harder of the two, implying a positivity bias toward the character with high utility over the character with low utility.

Finally, we hypothesized that participants would perceive both characters as nice, and would perceive the high utility character as the nicer of the two. Participants did perceive both characters as being nice (Helpful Character: $n=22$, observed proportion $=.92, p<.001$ in a binomial test; Low Utility Character: $n=24$, observed proportion $=1.00, p<.001$ in a binomial test). However, they did not rate the Helpful Character as the nicer of the two (Helpful Character, $n=15$, observed proportion $=.68$; Low Utility Character: $n=9$, observed proportion $=.38$; onetailed binomial test: $p=.154)$.

Children view characters who each demonstrate high levels of effort yet vary in levels of utility as helpful, as working hard, and as nice. They seem to perceive little difference in the two characters when endorsing one character's novel word over the other. Children are able to detect differences in characters' demonstrated utility at some level, however, as they rate the Helpful Character as more helpful and as working harder than the Low Utility Character.

\section{Condition 3: Helpful vs. No Social Context (but high effort) condition}

In the helpful vs. no social context yet high effort condition, we hypothesized that participants would prefer to learn novel words from characters acting in a social context over those not acting in a social context. In four trials, participants did not show a strong preference for learning novel words from the Helpful Character as compared to the No Social Context Character, $M=2.29, S D=0.91, S E=0.19$, however, there was a trend toward choosing the 
Helpful Character $t(23)=1.574, p=.129, d=0.66$ according to a single-sample $t$-test. This trend in the small sample size indicates that children endorse labels for novel words differently when the opposing characters vary in social context, and therefore utility.

We next hypothesized that participants would perceive the social context, but not the no social context, character as having been helpful, and would perceive the social context character as being the more helpful of the two. Participants perceived both characters as helpful (Helpful Character: $n=21$, observed proportion $=.88, p<.001$ in a binomial test; No Social Context Character: $n=19$, observed proportion $=.79, p<.001$ in a binomial test). There was a trend toward rating the Helpful Character as the more helpful of the two (Helpful Character, $n=16$, observed proportion $=.67$; No Social Context Character: $n=8$, observed proportion $=.33$; onetailed binomial test: $p=.076)$.

We then hypothesized that participants would perceive both characters as having worked hard, as they both demonstrated high effort, and yet would perceive the social context character as having worked the harder of the two. Participants did perceive both characters as having worked hard (Helpful Character: $n=21$, observed proportion $=.88, p<.001$ in a binomial test; No Social Context Character: $n=22$, observed proportion $=.92, p<.001$ in a binomial test). The Helpful Character was significantly rated as having worked the harder of the two (Helpful Character, $n=17$, observed proportion $=.71$; No Social Context Character: $n=7$, observed proportion $=.29$; one-tailed binomial test: $p=.032$ ). As in the Helpful vs. Low Utility condition, when the Helpful Character is paired with a character who has high effort yet low or no utility, children exhibit a bias toward the high utility character even when making an unrelated judgment of who worked harder.

Finally, we hypothesized that participants would perceive the social context, but not the 
no social context, character as nice; and would perceive the social context character as the nicer of the two. Participants perceived both characters as being nice (Helpful Character: $n=22$, observed proportion $=.92, p<.001$ in a binomial test; No Social Context Character: $n=22$, observed proportion $=.92, p<.001$ in a binomial test). Participants did not significantly rate one character as nicer than the other (Helpful Character, $n=13$, observed proportion $=.54$; No Social Context Character: $n=11$, observed proportion $=.46$; one-tailed binomial test: $p=.419$ ).

Children viewed both the high utility and no utility (no social context) characters as being helpful, as having worked hard, and as being nice. However, children did perceive a difference in the characters, as they trended toward a preference for the Helpful Character when asked to endorse one character's provided novel word over the other's. They also demonstrated a perceived difference by rating the Helpful Character as having worked harder than the No Social Context Character and trending toward rating the Helpful Character as more helpful.

\section{Discussion}

The current study aimed to better understand how children perceive and make epistemic decisions about informants, particularly those who vary in effort and utility, two important components of the warmth dimension of social cognition (e.g., Fiske et al., 2007). Participants did not have a preference when considering characters who varied in effort but not in utility when choosing whom to trust in a novel word learning task. The results were somewhat stronger when participants were asked to choose between characters who varied in utility but not in effort. Results were stronger still when participants compared a high utility character to a "no utility" character who was removed from any social context. Participants' perceptions of characters were generally more nuanced in the explicit judgment items (i.e., choosing which character was more 
helpful, worked harder, or nicer). Children seem to favor characters who possess high levels of utility to those with low utility or no utility.

There are several limitations to this study which may account for the results of the novel word endorsement items and the more compelling results of the explicit judgment items. First, children may not have generalized information learned in the scenarios presented to the novel word endorsement items. It would be desirable to conduct another study in which the training and testing item domains are more closely linked. Secondly, more conclusive results would likely be found if this study were continued or conducted again with greater numbers of participants. Several trends in the data fell just short of significance, particularly in Conditions 2 and 3, as noted above. Another possibility is that children of this age are yet incapable of actively applying the insight they gain about characters in the training phase to the task of making epistemic judgments in the novel word task. This would mirror previous results indicating that children can detect deception by the age of 4, but can only apply this understanding when making epistemic decisions beginning at the age of 5 (Vanderbilt et al., 2011). Finally, it should be noted that this study tested the limits of children's working memory. Given that children did not have consistent results on the memory check items, it may be that they were simply unable to track the complex information which was provided about each character.

Future research could examine the issue of children's epistemic judgments in the warmth domain of social cognition from other angles which were not investigated in the current study. For example, replicating this study with altered conditions would serve to further understanding of this field. As an example, the current study only presented characters who either possessed positive qualities (e.g., high effort, high utility) or else lacked those particular attributes. Future research could examine how children respond to characters who possess specifically negative 
qualities such as: various combinations of low effort, irrelevancy, and hindrance / obstruction of a goal (i.e., the opposite of high utility). Continuing to investigate the implications of the "no social context" condition from this study in comparison to other conditions would be of particular interest.

Learning about the world happens often in the context of personal interactions; yet these interactions may not always be with helpful or competent individuals who are both able and willing to satisfactorily instruct the learner (Shafto et al., 2012). Because of this, it becomes necessary for learners, particularly young children, to become capable of taking a critical stance toward informants in potentially epistemic situations (Mills, 2013). This study sought to further uncover the processes by which these epistemic judgments occur, specifically in the "warmth" dimension of social cognition (Fiske et al., 2007). By examining how children perceive and make decisions regarding characters varying in effort and utility, we learned that children are likely inclined to attend more closely to the utility of an informant's actions (helpfulness, usefulness, serviceableness) than to an informant's high exertion of effort. 


\section{References}

Aguiar, N. R., Stoess, C. J., \& Taylor, M. (2012). The Development of Children's Ability to Fill the Gaps in Their Knowledge by Consulting Experts. Child Development, 83(4) 13681381. doi: 10.1111/j.1467-8624.2012.01782.x

Boseovski, J. J. (2012). Trust in testimony about strangers: Young children prefer reliable informants who make positive attributions. Journal Of Experimental Child Psychology, 111(3), 543-551. doi:10.1016/j.jecp.2011.10.008

Brosseau-Liard, P.E., \& Birch, S.A.J. (2010). "I bet you know more and are nicer too!": What children infer from others' accuracy. Developmental Science, 13, 772-778. doi: 10.1111/j.1467-7687.2009.00932.x

Cluver, A., Heyman, G., \& Carver, L. J. (2013). Young children selectively seek help when solving problems. Journal Of Experimental Child Psychology, 115(3), 570-578. doi:10.1016/j.jecp.2012.12.011

Danovitch, J. H., \& Keil, F. C. (2007). Choosing between hearts and minds: Children's understanding of moral advisors. Cognitive Development, 22(1), 110-123. doi:10.1016/j.cogdev.2006.07.001

Effort, n. [Def. 2a]. (n.d.). In OED Online (September 2014 ed.). Retrieved from http://www.oed.com.echo.louisville.edu/view/Entry/59799? rskey=jaI7m7\&result=1

Fiske, S. T., Cuddy, A. C., \& Glick, P. (2007). Universal dimensions of social cognition: Warmth and competence. Trends In Cognitive Sciences, 11(2), 77-83. doi:10.1016/j.tics.2006.11.005

Koenig, M. A., \& Harris, P. L. (2005). Preschoolers mistrust ignorant and inaccurate speakers. Child Development, 76(6), 1261-1277. doi:10.1111/j.1467-8624.2005.00849.x 
Koenig, M. A., \& Jaswal, V. K. (2011). Characterizing children's expectations about expertise and incompetence: Halo or pitchfork effects? Child Development, 82(5), 1634-1647. doi:10.1111/j.1467-8624.2011.01618.x

Landrum, A. R., Mills, C. M., \& Johnston, A. M. (2013). When do children trust the expert? Benevolence information influences children's trust more than expertise. Developmental Science, 16(4), 622-638. doi:10.1111/desc.12059

Lane, J. D., Wellman, H. M., \& Gelman, S. A. (2013). Informants' traits weigh heavily in young children's trust in testimony and in their epistemic inferences. Child Development, 84(4), 1253-1268. doi:10.1111/cdev.12029

Liu, D., Vanderbilt, K. E., \& Heyman, G. D. (2013). Selective trust: Children's use of intention and outcome of past testimony. Developmental Psychology, 49(3), 439-445. doi:10.1037/a0031615

Lutz, D. J. \& Keil, F. C. (2002). Early Understanding of the Division of Cognitive Labor. Child Development, 73(4), 1073-1084. doi:10.1111/1467-8624.00458

Mascaro, O., \& Sperber, D. (2009). The moral, epistemic, and mindreading components of children's vigilance towards deception. Cognition, 112(3), 367-380. doi:10.1016/j.cognition.2009.05.012

Mills, C. M. (2013). Knowing when to doubt: Developing a critical stance when learning from others. Developmental Psychology, 49(3), 404-418. doi:10.1037/a0029500

Shafto, P., Eaves, B., Navarro, D. J., \& Perfors, A. (2012). Epistemic trust: Modeling children's reasoning about others' knowledge and intent. Developmental Science, 15(3), 436-447. doi:10.1111/j.1467-7687.2012.01135.x

Utility [Def. 1a]. (n.d.). In OED Online (September 2014 ed.). Retrieved from 
http://www.oed.com.echo.louisville.edu/view/Entry/220771?redirectedFrom=utility

Vanderbilt, K. E., Liu, D., \& Heyman, G. D. (2011). The development of distrust. Child

Development, 82(5), 1372-1380. doi:10.1111/j.1467-8624.2011.01629.x 